\title{
CLINICAL AND RADIOGRAPHIC EVALUATION OF LEDERMIX MATE- RIAL VERSUS FORMOCRESOL AS A CAPPING MATERIAL FOR PULP- OTOMIZED PRIMARY TEETH
}

\author{
Kelifa $\mathrm{M}^{*}$, AboElhassan $\mathrm{M}^{* *}$, Abdullah $\mathrm{A}^{* * *}$, Elmansy $\mathrm{T}^{* * * *}$
}

\section{ABSTRACT}

Objective: The aim of the present study was directed to evaluate clinically and radiographically the effect of Ledermix material versus formocresol as a capping material for pulpotomized primary teeth. Materials and methods: This study was performed on 60 primary molars. Children of 4-8y age were selected from the pediatric dental outpatients' clinic, faculty of dental medicine, Al-Azhar University. The teeth were divided into 2 main groups. Each group formed of 30 primary molars. Group A: 30 primary molars were capped using formocresol. Group B: 30 primary molars were capped using Ledermix. The teeth were assessed clinically and radiographically at 3 different intervals (1-day post-operative, 1 month, and 3 months), using standard clinical and radiographic criteria. Results: It was found that Ledermix offered good clinical and radiographical results when compared with formocresol but with no statistically significant differences. Formocresol vital pulpotomy (group A) showed $86,7 \%$ success rate, while the Ledermix vital pulpotomy technique (group B) showed a higher success rate (90\%). Conclusion: Ledermix vital pulpotomy has better prognosis compared to formocresol. However, the difference between them is not statistically significance.

Key words: Ledermix, formacresol, pulp capping material, primary teeth

\section{INTRODUCTION}

Oral health is a major public health issue affecting all groups of the population. Poor oral health during childhood is directly associated to poor oral health outcomes in childhood and throughout adulthood, as people remain susceptible to developing dental caries throughout their lives. Studies have demonstrated the link between oral health and other health issues. Early childhood caries (ECC) can lead to compromised health including diabetes and cardiovascular disease. The World Health Organization (WHO) understands the major impact of oral health on the individual health, as well as the population, and they placed major emphasis on improving oral health in all populations ${ }^{(1)}$.
Primary dentition is important for the well-being of children to provide them with functional, nonpathologic and healthy condition. Affected primary teeth should be managed to guard against premature loss which may lead to possible space loss and malocclusion. Dental caries is the most common chronic disease of childhood. One-quarter $(25 \%)$ of children aged $2-5$ and half $(50 \%)$ of children aged 12-15 suffer from tooth decay. Nearly $25 \%$ of adults aged 20-64 report having untreated dental caries, which at any age can lead to pain, tooth loss, and infection ${ }^{(2)}$.

According to the American Academy of Pediatric Dentistry (AAPD), children younger than three years of age, any sign of smooth-surface caries is an

\footnotetext{
* B.D.S, Al-Azhar University (Assiut branch).

** Professor of pedodontics and oral health, AL-Azhar university.

*** Ass professor of pedodontics and oral health, AL-Azhar university.

**** Lecturer of Pedodontics and oral health, AL-Azhar university.
} 
indicative of severe ECC. Teeth are at risk of dental decay as soon as they erupt into the oral cavity. ECC commonly appear on the upper anterior teeth, other teeth can also be affected. Dental caries is a multifactorial disease with an etiology that involves a complex interaction between biological, social and economic factors ${ }^{(3)}$.

ECC can be prevented and reversed in the initial stages. However, without appropriate and timely control, cariogenic bacteria may seriously destroy the hard-dental tissues and consequently affect the dental pulp ${ }^{(4)}$. Pulpotomy is one of the most used frequently treatment for retaining carious pulp involved primary teeth that would otherwise be extracted. Different materials have been used for performing pulpotomies of primary teeth. Formocresol (FC) has been a popular material of choice for pulpotomy procedure in the primary teeth, because of its ease in use and excellent clinical success. Concerns have been expressed about Formocresol pulpotomy because of inflammation and necrosis, cytotoxicity, systemic disturbance, mutagenic, carcinogenic potential and immunologic response ${ }^{(5)}$.

Alternative dressing materials such as $\mathrm{NaOCl}$, MTA, calcium hydroxide $(\mathrm{CH})$, collagen, ferric sulfate(FS), Bio active glass, and bone morphogenic protein (BMP) ...etc., have been suggested as possible replacements for formocresol in vital and non-vital pulp therapy with varying success rate ${ }^{(6)}$. Therefore, the aim of this study was to assess the clinical and radiographic effect of Ledermix material as a capping material for pulpotomized primary teeth

\section{MATERIALS AND METHODS}

Sixty children (4-8 years old) with badly decayed primary molars without pulp involvement were selected from outpatient clinic of the Department of Pedodontics and Oral health, faculty of Dental medicine, Al-Azhar University, Cairo. The criteria for selection of the children to be treated were: (1) Children having carious primary molars indicated for restoration. (2) Patients should be healthy with no systemic disease. (3) Children with a behavior rating of 3 or 4 on the Frankl. (4) Absence of clinical signs or symptoms suggesting non-vital tooth such as a suppurating sinus, soft tissue swelling, mobility or tenderness to percussion. (5) Possibility for establishing a final restoration of the tooth exclusion criteria were (1) History of spontaneous, unprovoked toothache. (2) Mobility, (grade I, II and III). (3) Sensitivity for percussion. (4) Presence of fistulae. (5) Peripheral or internal root resorption. (6) Carious furcation involvement. (7) Periapical lesions.

Molars also should meet the following radiographic criteria: (1) The root shouldn't have pathological resorption or not completely formed. (2) No pathological external or internal root resorption. (3) No interradicular or periodical radiolucency. (4) No calcific pulp degeneration. calcification of the pulp.

Preoperative assessment: A) Clinical evaluation; (1) Soft tissue status and oral hygiene was assessed. (2) Tooth vitality. B) Radiographic evaluation; Periapical dental film (standard long cone paroling technique) was done for each patient to have information about presence or absence of periodontal or periapical pathosis. The study was approved by Ethical Committee of Faculty of Dental Medicine, Boys, Cairo, Al-Azhar University. The work was discussed briefly, and every Patient's parent was signed an informed written consent form.

Radiographic interpretation After a complete history was obtained and a thorough clinical examination was conducted, periapical radiographs of the intended tooth were obtained prior treatment from every child included in the study. Digital periapical $x$-ray films were taken by RVG Kodak sensor at definite intervals (preoperative, 24hours postoperative, after 1month and after 3 months). 
The children were classified according to capping materials into two equal groups; each group comprised of (30) primary molars teeth.

Group (1); Comprising of 30 primary molars that received vital FC pulpotomy technique.

Group (2); Comprising of 30 primary molars that received Ledermix pulpotomy technique.

A) Formocresol pulpotomy: FC wet sterile cotton pellet was applied to canal orifices after homeostasis for 5 minutes (for vital pulpotomy), then thick layer of enforced ZOE was placed over the amputated pulp orifices after removal of cotton pellet then, a layer of zinc phosphate cement was placed as temporary filling for 3 months, then tooth restored with final restoration and stainless-steel crown.

B) Ledermix pulpotomy: Creamy paste-like mixture of Ledermix [(powder: zinc oxide $47.2 \%$, calcium hydroxide $33.4 \%$, triamcinolone and demeclocycline) (The majority of the liquid is eugenol 85\%)] was placed over the amputated pulp after homeostasis (figure 1). Then, a layer of zinc phosphate cement was placed as temporary filling for 3 months, then the tooth was restored with final restoration and stainlesssteel crown.

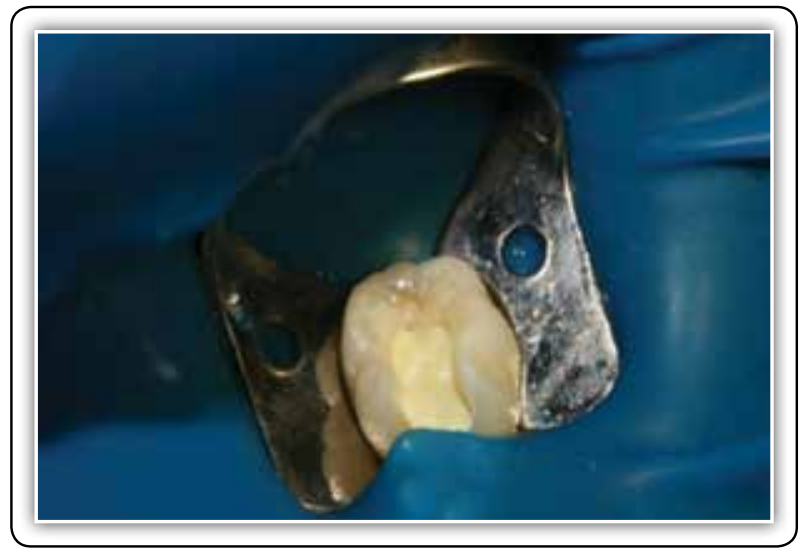

Fig. (1) Ledermix pulpotomy
The criteria for success were based on clinical and radiographic evidence

Clinical criteria of success:

1. No history of pain or discomfort.

2. No sensitivity to percussion.

3. No mobility.

\section{Radiographic criteria of success:}

1. No internal or external resorption.

2. No periodontal ligament space widening.

3. No apical or bifurcation radiolucent areas.

4. Radiographic evidence of continued root development with normal attempts of apex closure in pulpotomized molars. If any item in the previously mentioned criteria of success was not fulfilled, the case was considered a failure. The failed cases were treated with suitable primary teeth pulp therapy according to tooth condition.

\section{Data collection:}

Clinical and radiographic [standardized periapical x-ray films] data of the two groups were collected and tabulated at the definite intervals, [preoperative, 24hours post-operative, 1 month and 3 months].

\section{Statistical Analysis:}

The significant differences between any two groups were assessed by Student's $t$-test. The differences between multiple groups were assessed by one-way analysis of variance (ANOVA)followed by the Fisher's exact test. Values of $\mathrm{P} \leq 0.05$ were considered significant. These analyses were done using SPSS 20.0 statistical software.

\section{RESULTS}

The mean and standard deviation values were calculated for each group in each test. Data were explored for normality using Kolmogorov-Smirnov and Shapiro-Wilk tests, data showed non-parametric distribution. 
For non-parametric data; Mann-Whitney was used to compare between two groups in nonrelated samples. Friedman test was used to compare between more than two groups in related samples.

Wilcoxon was used to compare between two groups in related samples. The significance level was set at $\mathrm{P} \leq 0.05$. Statistical analysis was performed with IBM ${ }^{\circledR}$ SPSS ${ }^{\circledR}$ Statistics Version 20 for Windows

\section{CLINICAL EVALUATION:}

\section{Redness/Swelling: (graph 1)}

\section{A) Relation between time intervals}

\section{Formocresol:}

There was a statistically significant difference between (After 1 day), (After 1 month) and (After 3 months) groups where $(p=0.018)$.

\section{Ledermix:}

There was a statistically significant difference between (After 1 day), (After 1 month) and (After 3 months) groups where $(p=0.050)$.

\section{B) Relation between groups in each time intervals:}

\section{After 1 day:}

There was no statistically significant difference between (Formocresol) and (Ledermix) groups where $(p=1)$.

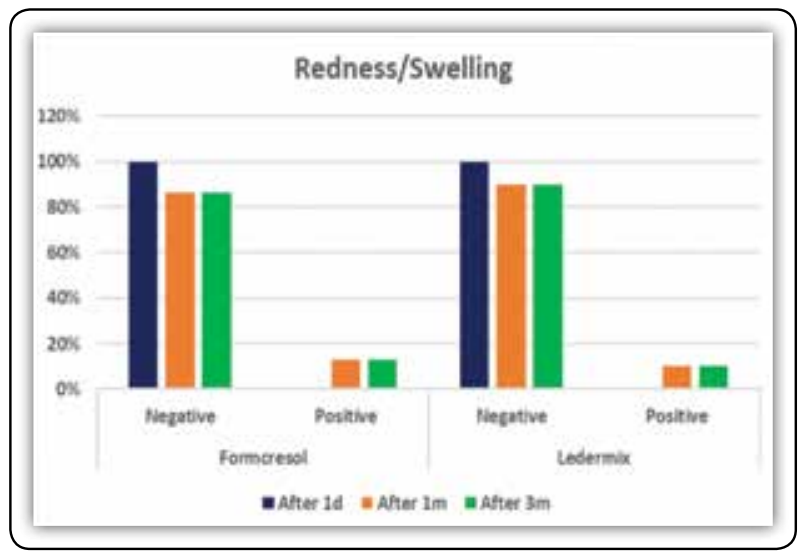

Graph (1) Shows redness and swelling evaluation in relation between time and formocresol and Ledermix pulpotomy

\section{After 1 month:}

There was no statistically significant difference between (Formocresol) and (Ledermix) groups where $(p=0.690)$.

\section{After 3 months:}

There was no statistically significant difference between (Formocresol) and (Ledermix) groups where $(p=0.690)$.

\section{Pain:}

\section{Relation between time intervals: (graph 2)}

\section{Formocresol:}

There was a statistically significant difference between (After 1 day), (After 1 month) and (After 3 months) groups where $(p=0.002)$.

\section{Ledermix:}

There was a statistically significant difference between (After 1 day), (After 1 month) and (After 3 months) groups where $(p=0.011)$.

Relation between groups in each time intervals:

\section{After 1 day:}

There was no statistically significant difference between (Formocresol) and (Ledermix) groups where $(p=1)$.

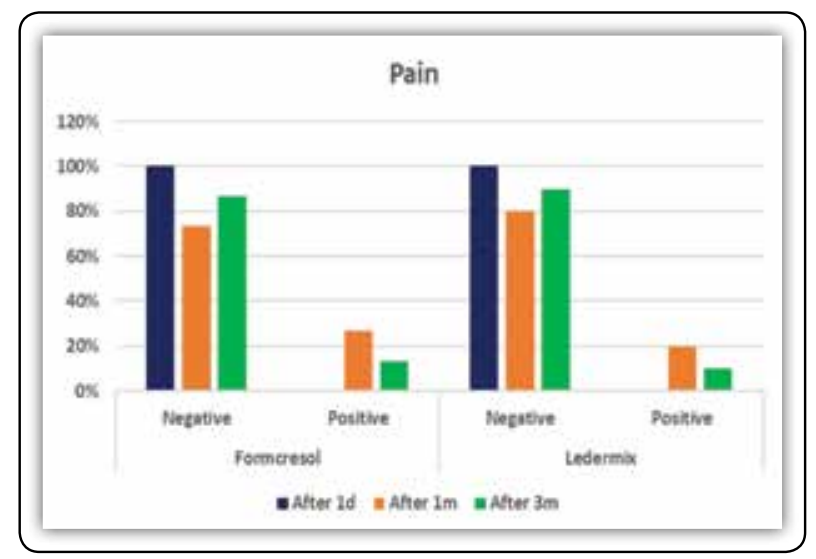

Graph (2) Shows pain evaluation in relation between time and formocresol and Ledermix pulpotomy 


\section{After 1 month:}

There was no statistically significant difference between (Formocresol) and (Ledermix) groups where $(p=0.545)$.

\section{After 3 months:}

There was no statistically significant difference between (Formocresol) and (Ledermix) groups where $(p=0.690)$.

\section{Radiographic evaluation:}

\section{PDL space: (graph3)}

Relation between time intervals:

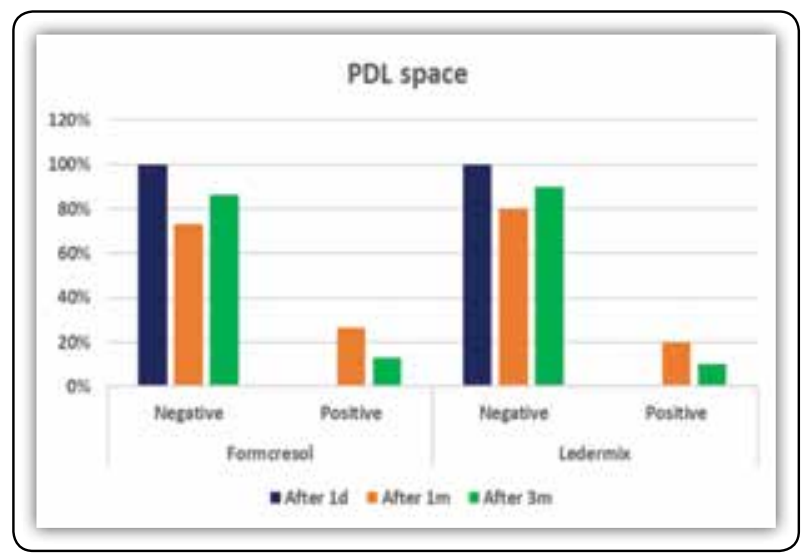

Graph (3) Shows radiographic pdl space evaluation in relation between time and formocresol and ledermix pulpotomy

\section{Formocresol:}

There was a statistically significant difference between (After 1 day), (After 1 month) and (After 3 months) groups where $(p=0.002)$.

\section{Ledermix:}

There was a statistically significant difference between (After 1 day), (After 1 month) and (After 3 months) groups where $(p=0.011)$.

\section{B) Relation between groups in each time intervals: \\ a) After 1 day:}

There was no statistically significant difference between (Formocresol) and (Ledermix) groups where $(p=1)$.

\section{b) After 1 month:}

There was no statistically significant difference between (Formocresol) and (Ledermix) groups where $(p=0.545)$.

\section{c) After 3 months:}

There was no statistically significant difference between (Formocresol) and (Ledermix) groups where $(p=0.690)$

\section{2- Periapical radiolucency:}

Relation between time intervals: (graph 4)

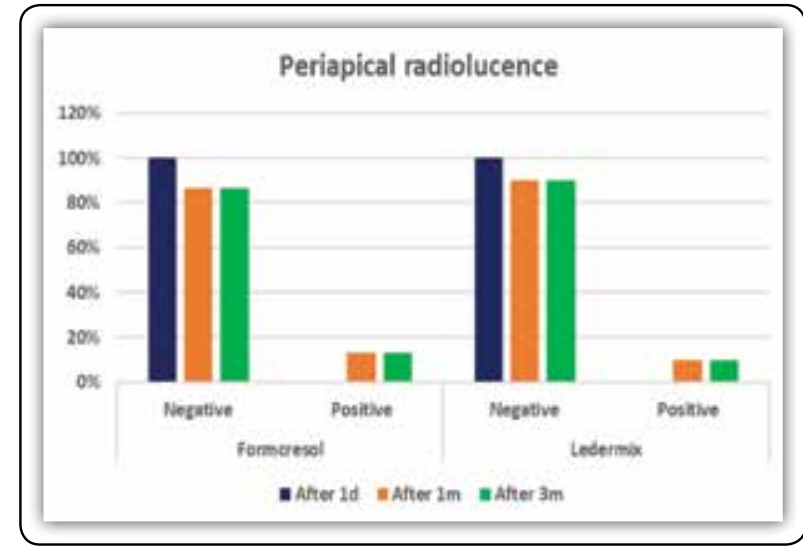

Graph (4) Shows preapical radiolucency evaluation in relation between time and formocresol and Ledermix pulpotomy 


\section{Formocresol:}

There was a statistically significant difference between (After 1 day), (After 1 month) and (After 3 months) groups where $(p=0.018)$.

\section{Ledermix:}

There was a statistically significant difference between (After 1 day), (After 1 month) and (After 3 months) groups where $(p=0.050)$.

Relation between groups in each time intervals:

\section{After 1 day:}

There was no statistically significant difference between (Formocresol) and (Ledermix) groups where $(p=1)$.

\section{After 1 month:}

There was no statistically significant difference between (Formocresol) and (Ledermix) groups where $(p=0.690)$.

\section{After 3 months:}

There was no statistically significant difference between (Formocresol) and (Ledermix) groups where $(p=0.690)$, (figure 2).

\section{DISCUSSION}

In pediatric dentistry, Pulpotomy is still the most common treatment method in case of pulp exposure in asymptomatic primary molars ${ }^{(7)}$. The ideal pulpotomy agent should accelerate the recovery of remaining radicular pulp tissue to a healthy state so that involved tooth attains normal physiological state ${ }^{(8)}$. However, among different techniques and medicaments used in primary molar pulpotomy, formocresol had been popular pulpotomy medicament in the primary dentition for the past 60 years and is still of the material of choice in primary teeth pulpotomy in many countries ${ }^{(9)}$. On the other hand, there are growing concerns over the faith of formocresol and its wide use between dentists due to its potential toxicity and carcinogenicity ${ }^{(10)}$. So, in the last decades, several alternatives have been suggested to replace formocresol such as alendronate sodium, enamel matrix derivative, calcium hydroxide-formocresol mix, Mineral Trioxides Aggregate (MTA), ferric sulphate and bioactive glass.

Ledermix was suggested as an efficient pulp capping material as it possesses potent anti-inflammatory and antimicrobial properties. The main active components present in Ledermix are triamcinolone (corticosteroid) and demeclocycline (a tetracycline antibiotic)

The current study investigates the availability of using Ledermix material as a biocompatible pulp capping medicament in primary molars after three months of clinical and radiographic follow up in compare to formocresol pulpotomy in vital pulp in primary molars.

In the present study, there was no statistically significant difference between Ledermix and formocresol pulpotomy:

In group A (FC pulpotomy), the success rate was approximately $(86,7 \%)$ since 26 teeth from 30 showed no signs and symptoms of inflammation clinically. while in group B (Ledermix pulpotomy) the success rate was approximately (90\%) since 27 teeth from 30 showed no signs and symptoms of inflammation clinically. The result of group (A) agreed with Moretti et al., 2008 and junior et al, 2015 recorded $87 \%$ success rate of FC pulpotomy. In addition, this study results agree with Alaçam et al., 2009 and Godhi Brinda, 2011, They were recorded $(87 \%)$ and $(89 \%)$ success rate of $5 \mathrm{~min}$ formocresol pulpotomy ${ }^{(11-14)}$

Also, El Sadek et al., (2016) and Ruby et al., (2013) reported 100\% success and this high success rate could be attributed to that he left the FC pellet in place for a longer time $(5-10 \mathrm{~m})$ and filled the chamber with a $\mathrm{Zn} \mathrm{OE-Zn} \mathrm{acetate-one} \mathrm{drop} \mathrm{of} \mathrm{FC}$ base $^{(15,16)}$. 
The higher clinical and radiographic success rate of formocresol vital pulpotomy (Group A) in our study was attributable to its germicidal action. The chemical bonding with the microorganism's proteins and fixatives qualities is the basis of bactericidal action of formocresol. Although the study is imperative to suggest the clinical and radiographic success, it is difficult to forego the actions which are present due to the chemical action of the formaldehyde with reference to fixation with the protein ${ }^{(17,18)}$.

However, the success rate of formocresol in the present study was lower than that suggested by others $^{(19)}$.

In their study, $100 \%$ clinical success rate with formocresol was reported. The failure was in the form of pain with percussion on the treated teeth, grade II mobility and redness in the mucobuccal fold. Additionally, radiographic examination revealed widened periodontal ligament space, periapical and furcation radiolucency with varying degrees. An explanation of that failure could be due to the presence of chronic inflammation in the residual pulp at the time of treatment and as such leading to diagnostic errors. An inherent problem in treating any exposed pulp is the lack of ability of clinicians to accurately diagnose the precise pathological state of the pulp of an extensively carious tooth. This is more difficult in children where the patients' responses to pulp testing procedures are unreliable. In addition, the level of bacterial penetration cannot be determined clinically. Therefore, there may be cases where a clinician has followed routine procedure to remove all caries but some bacteria have already penetrated into the radicular pulp tissue $^{(20)}$.

Moreover, bacteria within the pulp tissue could still have come from the blood stream, since the inflammation due to the dental injury causes vasodilatation and an increase of vessel permeability, making the transport of bacteria through the hematogenic way possible. It is known that this phenomenon, named anachoresis, consists in the performance of circulating microorganisms, foreign proteins and other substances in inflammatory areas. By means of this hypothesis, it may deduce that cavity preparations with pulp exposure become favorable to anachoresis, where microorganisms may persist or even collaborate for more bacterial colonization $^{(21)}$

In our study the promising clinical outcome of vital pulpotomy performed with Ledermix $(90 \%$ success rate) may be explained on the bases that was found to possess potent anti-inflammatory and antimicrobial properties. Triamcinolone that was found in Ledermix has anti-inflammatory action which assists with rapid pain relief following the treatment. It also inhibits clastic cells (osteoclasts, cementoclasts and dentinoclasts) and therefore it can be used to manage root resorption. Demeclocycline that found in ledermix materials has antimicrobial action and it also has some limited ability to inhibit the clastic cells involved in root resorption ${ }^{(22-24)}$.

The result of group B was supported with study of suction n (2009), reported that Ledermix cement can be used as a pulp-capping agent and if the dentine is hypersensitive, it can be used as a temporary sub lining for deep cavities where no exposure has occurred. Ledermix not only provides effective pain relief in the emergency management of irreversible pulpitis, but also forms an excellent sub lining for both temporary and more permanent restorations. Perfect for use in endodontic therapy and between appointments, Ledermix is water soluble and is easily rinsed out for obturation to be carried out ${ }^{(25)}$.

Abbott $\mathrm{p}$ et al, (1989) reported that there was significantly less demeclocydine reaching the periodontal tissues when Ledermix was mixed with Pulpdent, the demeclocydine was maintained in the root canal itself simply because of the slower release. This higher residual amount of antibiotic 
may be advantageous in the treatment of extremely large periapical lesions using long-term intracanal dressings. Also, it would help to maintain sterility of the canal and the tooth. This study has shown that mixing these two pastes potentiates the antibacterial efficacy of Ledermix than when Ledermix is used alone, and less frequent changing of the dressing should be required ${ }^{(26)}$.

And supported by study for Moskow (1984) and Negm, (2001) shown a predictable means of eliminating bacteria from root canal systems and a reliable method for reducing periapical inflammation and periodontal ligament effect and stimulating hard tissue formation. In general, it takes 10-15 days for an inflammation to subside. The use of anti-inflammatory medicaments can provide rapid relief of symptoms. Corticosteroids as content of ledermix have been suggested for the management of postoperative pain in endodontics ${ }^{(27,28)}$.

In the present study, radiographic investigation revealed an improvement, at the end of the follow up period (3 months), with both ledermix and formocresol treated teeth. This was seen through a gradual decrease of radiolucency throughout the follow up period. This finding agrees with other investigators, since clinical and radiographic results revealed success at the afore mentioned interval, if the recall periods were continued longer, complete resolution of these changes could be occurred ${ }^{(29)}$.

However, Ledermix proved promising better healing ability and positive responses than formocresol in vital pulpotomy. Statistical analysis revealed no significant difference between the effects of both medicaments on the clinical and radiographic outcomes of vital pulp therapy.

\section{CONCLUSION}

Ledermix vital pulpotomy has better prognosis compared to formocresol. However, the difference between them is not statistically significance.

\section{REFERENCE}

1. Kay E, Locker D. Is dental health education effective? A systematic review of current evidence. Community Dent and oral epidem . 1996;24(4):231-5.

2. Edelstein B, Chinn C, Laughlin R, Lumsden C. Early childhood caries: Definition and epidemiology. Early childhood oral health. 2009;1:18-49.

3. Pediatrics A. Policy on early childhood caries (ECC): classifications, consequences, and preventive strategies. Ped Dent. 2008;30(7 Suppl):40.

4. Gonzalez A, Ruiz M, Pierdant M, Garroch J, Pozos A. Zinc Oxide-eugenol pulpotomy in primary teeth: a 24-month follow-up. Ped Dent. 2016;40(2):107-12.

5. Bagrizan M, Pourgolshani P, Hosseinpour S, Jalalpour G, Shahrestani M. Plasma Level Formaldehyde in Children Receiving Pulpotomy Treatment under General Anesthesia. Ped Dent. 2017;41(2):95-101.

6. Fuks A. Vital pulp therapy with new materials for primary teeth: new directions and treatment perspectives. Ped Dent. 2008;30(3):211-9.

7. Vij R, Coll J, Shelton P, Farooq N. Caries control and other variables associated with success of primary molar vital pulp therapy. Ped Dent. 2004;26(3):214-20.

8. Seale N, Coll J. Vital pulp therapy for the primary dentition. General Dent. 2010;58(3):19-200; quiz 1-2.

9. Huth K, Paschos E, Hajek-Al-Khatar N, Hollweck R, Crispin A, Hickel R, et al. Effectiveness of 4 pulpotomy techniques--randomized controlled trial. J Dent Res. 2005;84(12):1144-8.

10. Lewis B. Formocresol in dentistry. Br Dent J. 2008; 204(9):477.

11. Moretti A, Sakai V, Oliveira T, Fornetti A, Santos F, Machado $\mathrm{M}$, et al. The effectiveness of mineral trioxide aggregate, calcium hydroxide and formocresol for pulpotomies in primary teeth. Endo J. 2008;41(7):547-55.

12. Stringhini E, Vitcel M, Oliveira L. Evidence of pulpotomy in primary teeth comparing MTA, calcium hydroxide, ferric sulphate, and electrosurgery with formocresol. European archives of paediatricdentistry. J Euro Ped Dent 2015;16(4):303-12

13. Alacam A, Odabas E, Tuzuner T, Sillelioglu H, Baygin O. Clinical and radiographic outcomes of calcium hydroxide 
and formocresol pulpotomies performed by dental students. Oral Surg. 2009;108(5):127-33.

14. Godhi B, Sood P, Sharma A. Effects of mineral trioxide aggregate and formocresol on vital pulp after pulpotomy of primary molars: An in vivo study. Clinic Dent. 2011;2(4):296-301.

15. El Meligy O, Allazzam S, Alamoudi N. Comparison between biodentine and formocresol for pulpotomy of primary teeth: A randomized clinical trial. Quintessence $\mathbf{J}$. 2016;47(7).

16. Ruby J, Cox C, Mitchell S, Makhija S, CHOMPUI P, Jackson J. A randomized study of sodium hypochlorite versus formocresol pulpotomy in primary molar teeth. Ped Dent. 2013;23(2):145-52.

17. Akbar A. A five-year clinical study of formocresol treatment in 120 cases of pulpotomy in permanent molars. J pedo. $1987 ; 11(3): 242$.

18. Armstrong L, Patterson S, Kafrawy H, Feltman M. Comparison of Dycal and formocresol pulpotomies in young permanent teeth in monkeys. Oral Surg. 1979; 48(2):160-8.

19. Dean J, Mack R, Fulkerson B, Sanders B. Comparison of electrosurgical and formocresol pulpotomy procedures in children. Ped Dent. 2002;12(3):177-82.

20. Caicedo R, Abbott P, Alongi D, Alarcon M. Clinical, radiographic and histological analysis of the effects of mineral trioxide aggregate used in direct pulp capping and pulpotomies of primary teeth. Austr Dent J. 2006;51(4):297-305.
21. Briso ALF, Rahal V, Mestrener S, Dezan E. Biological response of pulps submitted to different capping materials. Brazil oral Res. 2006;20(3):219-25.

22. Pierce A, Lindskog S. The effect of an antibiotic/corticosteroid paste on inflammatory root resorption in vivo. Oral Surg. 1987;64(2):216-20.

23. Heithersay G, Hume W, Abbott P. Conventional root canal therapy, II: Intracanal medication. Harty FJ, Ed Endodontics in Clinical Practice 3rd Edition Dental Practitioner Handbook. 1990(24):162-85.

24. Pierce A, Heithersay G, Lindskog S. Evidence for direct inhibition of dentinoclasts by a corticosteroid/antibiotic endodontic paste. Dent Trauma. 1988;4(1):44-5.

25. SUCTION N. New products and focus on endodontics and facial aesthetics. Br Dent J. 2009;207(4):179.

26. Abbott P, Hume WR, Heithersay GS. Effects of combining Ledermix ${ }^{\circledR}$ and calcium hydroxide pastes on the diffusion of corticosteroid and tetracycline through human tooth roots in vitro. Dent Trauma. 1989;5(4):188-92.

27. Moskow A, Morse D, Krasner P, Furst M. Intracanal use of a corticosteroid solution as an endodontic anodyne. Oral Surg. 1984;58(5):600-4.

28. Negm M. Intracanal use of a corticosteroid-antibiotic compound for the management of posttreatment endodontic pain. Oral Surg. 2001;92(4):435-9.

29. Meyer F, Sayegh S. Wound healing following curettement of bifurcation abscesses of human primary molars. Oral Surg. 1979;47(3):267-74. 